\title{
Coupling GPS tracking with dive behavior to examine the relationship between foraging strategy and fine-scale movements of northern fur seals
}

\author{
Carey E. Kuhnn ${ }^{1, *}$, Yann Tremblay ${ }^{2}$, Rolf R. Ream ${ }^{1}$, Thomas S. Gelatt ${ }^{1}$ \\ ${ }^{1}$ National Marine Mammal Laboratory, Alaska Fisheries Science Center/National Marine Fisheries Service/NOAA, \\ 7600 Sand Point Way NE, Seattle, Washington 98115, USA \\ ${ }^{2}$ Institut pour la Recherche et le Développement, Centre de Recherche Halieutique Méditerranéenne et Tropicale, \\ Avenue Jean Monnet BP 171, 34203 Sete Cedex, France
}

\begin{abstract}
The foraging strategies of diving marine species are often categorized into 3 fundamental groups (epipelagic, mesopelagic, and benthic foraging) based on diving, habitat use, and diet studies. Because these foraging strategies are influenced by the distribution and behavior of the prey being targeted, we would expect search behavior and space use to differ depending on the strategy employed. Since northern fur seals Callorhinus ursinus display both epipelagic and benthic foraging strategies, they were an ideal model to test the hypothesis that fine-scale movement and space-use patterns will vary when animals use markedly different foraging strategies. Dive bouts were characterized into foraging strategies based on numerous dive parameters (depth, duration, etc.). For each strategy, we compared movement patterns (e.g. transit rate and path straightness) and space use (area-restricted search [ARS] zones) around St. Paul Island, Alaska, USA. Nearly all dive parameters were significantly different between foraging strategies (epipelagic vs. benthic). In addition, epipelagic bouts were more sinuous and covered a greater total distance than benthic bouts. However, the greater distances traveled in epipelagic bouts were due to longer bout durations, as transit rates were not different between the 2 strategies. On average, $<2$ ARS zones were identified per trip, and the characteristics of epipelagic and benthic ARS zones were not different. By combining dive behavior with precise at-sea locations, this study has provided a greater understanding of the finescale foraging behavior of northern fur seals. Monitoring changes in foraging behavior over time and comparing behavior among populations with differing population trajectories may provide more clues as to why northern fur seal numbers on St. Paul Island continue to decline.
\end{abstract}

KEY WORDS: Callorhinus ursinus $\cdot$ Fractal landscape analysis $\cdot$ Area-restricted search

\section{INTRODUCTION}

Understanding how animals exploit their environment is central in ecology and necessary for the protection of species and critical resources. Through a combination of information that has been gathered about diving behavior, habitat use, and diet, the foraging strategies of many air-breathing marine species have been classified into 3 fundamental patterns. Epipelagic foragers target prey within the water column at depths ranging from 0 to $200 \mathrm{~m}$, whereas mesopelagic species forage between $\sim 200$ and $1000 \mathrm{~m}$. In contrast, benthic or demersal predators feed on species that are found at or near the bottom, targeting continental shelf or shelf break regions of varying depths (Tremblay \& Cherel 2000, Costa \& Gales 2003, Villegas-Amtmann et al. 2008).

Within marine vertebrate classes and families, species that demonstrate each of the disparate foraging strategies have been identified. For example, both gentoo Pygoscelis papua and Adélie penguins $P$. adeliae feed on epipelagic prey, whereas yellow-eyed 
penguins Megadyptes antipodes forage benthically (Croxall et al. 1988, Naito et al. 1990, Mattern et al. 2007). Leatherback sea turtles Dermochelys coriacea feed on epipelagic, soft-bodied invertebrates such as jellyfish, whereas mature green turtles Chelonia mydas feed primarily on benthic sea grasses and algae (Hochscheid et al. 1999, Hays et al. 2006). Different species of pinnipeds also exhibit each of the fundamental foraging strategies. For example, subantarctic fur seals Arctocephalus tropicalis feed epipelagically, adult female northern elephant seals Mirounga angustirostris feed mesopelagically, and walrus Odobenus rosmarus feed benthically (Wiig et al. 1993, Georges et al. 2000, Le Boeuf et al. 2000). A few studies have even shown that intraspecific foraging strategies can vary between sexes (e.g. in northern elephant seals; Le Boeuf et al. 2000) or individuals (e.g. in Galapagos sea lions Zalophus wollebaeki; Villegas-Amtmann et al. 2008).

Given that these foraging strategies are partly shaped by variability in the distribution and behavior of prey, we would expect that, as predators target different prey species, search behavior and space use will differ depending on the foraging strategy employed. However, for many air-breathing marine species, it has been difficult or impossible to examine the fine-scale movements of individuals during distinct foraging periods due to limitations in position accuracy and frequency when using traditional Argos satellite tracking (Bradshaw et al. 2004). Nevertheless, recent advances in GPS technology are helping to overcome these challenges by providing the ability to examine the detailed movement patterns of marine species (Mattern et al. 2007, Schofield et al. 2007, Kuhn et al. 2009).

Previously, for species that spend much of their time underwater, traditional GPS instruments were ineffective for obtaining at-sea locations (Sisak 1998, Jay \& Garner 2002). With the development of Fastloc GPS technology (Bryant 2007), it is now possible to obtain the more accurate, consistently acquired locations that are currently available for tracking animals in the terrestrial environment (Mattern et al. 2007, Hazel 2009, Kuhn et al. 2009). Instruments that are equipped with Fastloc GPS are able to obtain satellite signals in milliseconds and can typically determine locations with an error of $<50 \mathrm{~m}$ (Bryant 2007). During stationary tests, Fastloc GPS instruments determined positions with an average error of $40 \pm 80.5 \mathrm{~m}$, and $95 \%$ of locations were $<102 \mathrm{~m}$ from the true location (Hazel 2009). In contrast, even the highest quality locations reported by Argos can have errors of up to $250 \mathrm{~m}$ (Argos 2006). Finally, these instruments are not limited to obtaining locations only when Argos satellites are overhead, resulting in a much higher temporal frequency of locations (Kuhn et al. 2009).
Given that fine-scale movement patterns of airbreathing marine species can now be measured, it is finally possible to examine how movement patterns vary between differing foraging strategies. Adult female northern fur seals Callorhinus ursinus, Linneaus 1758 are an ideal model to examine these differences without the confounding factors of sex, location, or season because they display both benthic and epipelagic foraging behaviors (Gentry et al. 1986, Goebel 1998). In addition, identifying patterns of movement that are related to these different foraging strategies is essential to understanding northern fur seal habitat use. This species was listed as 'depleted' under the Marine Mammal Protection Act in 1988, and the largest breeding colony in Alaska (St. Paul Island) has been declining at a rate of $\sim 6.0 \% \mathrm{yr}^{-1}$ (Towell et al. 2006, NMFS 2007). A greater understanding of foraging behavior and habitat use is vital to provide guidance for future conservation efforts and management of this species. Therefore, the objectives of this study were to (1) describe and quantify the different foraging strategies used by female northern fur seals during the breeding season, and (2) examine how fine-scale movement (e.g. transit rate, distance traveled, path straightness) and space-use (e.g. area-restricted search zones) patterns vary when animals employ differing foraging strategies.

\section{MATERIALS AND METHODS}

Animal handling. Research was conducted from September to October 2007 and August to October 2008 at St. Paul Island, Alaska (USA; Fig. 1). Forty-two adult female northern fur seals were instrumented at 2 rookeries: Reef $\left(\mathrm{n}=20 ; 57.1^{\circ} \mathrm{N}, 170.3^{\circ} \mathrm{W}\right)$ and Vostochni $\left(\mathrm{n}=22: 57.25^{\circ} \mathrm{N}, 170.1^{\circ} \mathrm{W}\right)$. Females that were observed to be nursing or calling for a pup were captured using hoop nets. Instruments were attached while animals were either physically restrained or sedated using gas anesthesia (isoflurane) that was administered with oxygen via a portable vaporizer. Each female was measured $( \pm 1 \mathrm{~cm})$ and weighed using a digital scale $( \pm 0.1 \mathrm{~kg})$. Animals were recaptured 6 to 52 d later, physically restrained for instrument removal, and reweighed prior to release.

Instrumentation. Each animal was equipped with an Mk10-AF tag (Wildlife Computers), which has an Argos satellite transmitter, Fastloc GPS, and timedepth recorder capabilities. Thirty of the females were also instrumented with an Mk10-L tag (Wildlife Computers), which only had time-depth recorder capabilities. The Mk10-AF tag used Fastloc technology to collect GPS locations at 15 min intervals when the animal was above the surface. Along with acquir- 


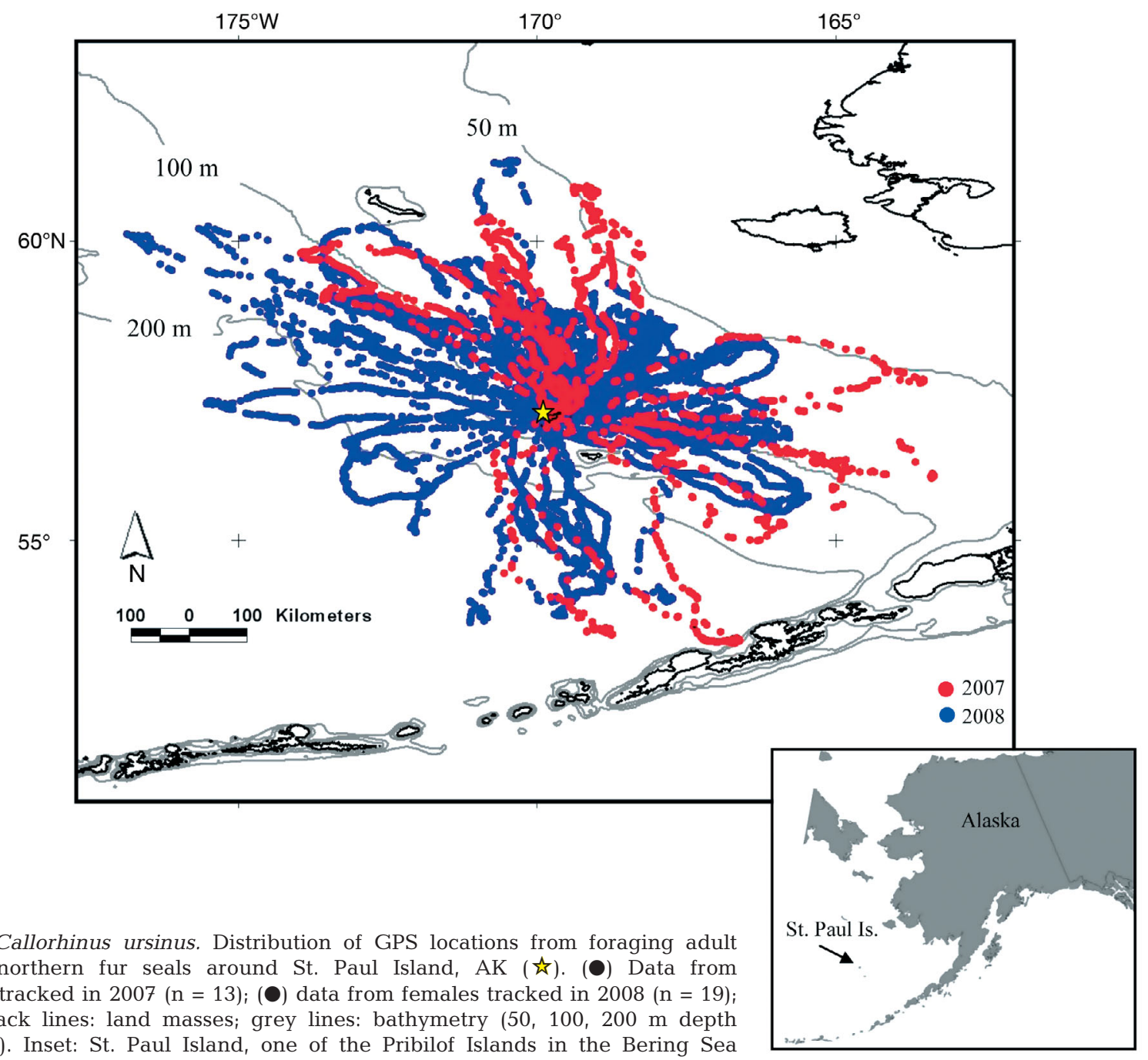

Fig. 1. Callorhinus ursinus. Distribution of GPS locations from foraging adult female northern fur seals around St. Paul Island, AK (㲾). (৩) Data from females tracked in 2007 ( $\mathrm{n}=13)_{\text {; }}(\bullet)$ data from females tracked in $2008(\mathrm{n}=19)_{\text {; }}$ Solid black lines: land masses; grey lines: bathymetry $(50,100,200 \mathrm{~m}$ depth contours). Inset: St. Paul Island, one of the Pribilof Islands in the Bering Sea

ing an Argos satellite position, the instrument was programmed to transmit a subset of the GPS data via the Argos system at the highest priority level. When archived GPS data were not recovered, transmitted GPS data were used.

In 2007, dive data from both Mk10-L and Mk10-AF instruments were sampled at 5 s intervals. In 2008, the Mk10-L and Mk10-AF tags sampled dive depth at 1 or $5 \mathrm{~s}$ intervals, respectively. Mk10-L tags were used in conjunction with stomach temperature telemeters (STT); however, only foraging trips where females no longer retained the STT were used for this study to reduce the possible influence of the STT on at-sea behavior. Finally, to facilitate instrument recovery, each female was equipped with a VHF tag (Advanced Telemetry Systems). Instruments were attached directly to the dorsal pelage using quick-set epoxy.

Dive data analysis. Dive data were processed using a purpose built zero-offset correction algorithm and analysis program written in MATLAB (IKNOS-DIVE,
IKNOS toolbox, Y. Tremblay unpubl.). A dive was defined by a minimum depth of $4 \mathrm{~m}$ and a minimum duration of $20 \mathrm{~s}$. Maximum dive depth, dive duration, and post-dive surface interval were calculated for each dive. Bottom time was calculated as the time between the first and last inflection points at $>80 \%$ of the maximum depth. Dive bouts were classified using log-survivorship curves based on the post-dive surface interval following the methods of Gentry \& Kooyman (1986). An inflection point on the curve signals the duration between consecutive dives (termed the bout ending criterion, BEC) that, if surpassed was deemed to end a bout. A BEC was determined for each foraging trip. The minimum criterion for a bout was 4 dives $>6 \mathrm{~m}$, with the post-dive surface interval of each dive falling within the BEC. In addition, to examine movement parameters, bouts with $<4$ GPS locations were removed because we believe they did not provide enough movement information to test the study hypothesis. 
The first goal of this study was to determine whether distinct foraging strategies are used by northern fur seals on St. Paul Island. Therefore, a hierarchical cluster analysis was used to classify dive behavior into foraging strategies using the Euclidean distance and average linking method. Bouts were independently clustered for each foraging trip. Input variables were the bout averages for dive depth (m), dive duration (s), bottom time (s), post-dive surface interval (s), descent rate $\left(\mathrm{m} \mathrm{s}^{-1}\right)$, ascent rate $\left(\mathrm{m} \mathrm{s}^{-1}\right)$, vertical excursions during the bottom phase (wiggles), total vertical distance covered during wiggles $(\mathrm{m})$, bottom range (difference between minimum and maximum vertical distance during wiggles, m), and dive efficiency (bottom time/[dive duration + post-dive interval]). Additionally, SDs of dive duration, dive depth, bottom time, postdive surface interval, total vertical distance, bottom range, and efficiency were used for classification.

To characterize the resulting groups of dive behavior, 2 independent variables were used: dive index (DI; dive depth/ocean depth) (Simmons et al. 2007) and intra-depth zone index (IDZ) (Tremblay \& Cherel 2003). The location for the start of each dive was determined by interpolating GPS data to each dive (see details of interpolation in 'GPS tracking data analysis'). Ocean depth was calculated using 2 min gridded global relief data (ETOP02v2). The IDZ indexed the degree of differences between the maximum depths that were achieved on consecutive dives. The IDZ range was calculated as the maximum depth that was reached in the preceding dive $\pm 10 \%$. An IDZ of 1 indicates that the dive fell within the IDZ range, while an IDZ of 0 indicates that a subsequent dive differed by $>10 \%$ of the previous maximum depth. Based on the differences in the 2 independent variables and average dive characteristics, the resulting dive groups were classified as epipelagic, benthic, or mixed foraging strategies.

Finally, for each foraging strategy, we examined whether there were significant differences in bout start time in relation to time of day. Due to the significant change in daylight hours over the tracking period, bouts were classified as starting either during the day or during the night based on local sunrise and sunset times for each day. Based on previous descriptions of pinniped dive behavior, we predicted that epipelagic bouts would start more often during night time hours when diel vertically migrating prey move to shallow waters, whereas benthic dive bouts would occur throughout the day when animals target nonmigrating prey on the bottom (Costa \& Gales 2003, Ream et al. 2005, Villegas-Amtmann et al. 2008).

GPS tracking data analysis. Erroneous GPS locations were filtered based on a maximum transit rate of $2.5 \mathrm{~m} \mathrm{~s}^{-1}$ (Tremblay et al. 2006, Kuhn et al. 2009).
Tracks were interpolated using a hermite curve to associate each dive with a location based on the methods described by Tremblay et al. (2006). The sum of distances between locations was used to calculate total distance travelled $(\mathrm{km})$. Average bout transit rate $(\mathrm{km}$ $\mathrm{h}^{-1}$ ) was calculated by dividing the total distance travelled by the bout duration. A straightness index was used to determine the sinuosity of the path by dividing the straight-line distance between the bout start and end locations by the total distance travelled (Weimerskirch et al. 2002).

In addition to changes in movement patterns, periods of area-restricted search (ARS) are often used to identify foraging behavior and important feeding habitats (Kareiva \& Odell 1987, Fauchald \& Tveraa 2003, Tremblay et al. 2007, Weimerskirch et al. 2007). Periods of ARS were determined using the fractal landscape method (Tremblay et al. 2007). First, speeds between successive interpolated locations were ranked. The distance traveled between locations was determined for the lowest third of the ranked speeds, and the speed that was associated with the longest distance was selected. This distance was then used to segment the seal's track around each location. The fractal dimension (fractal D) for each segment was calculated based on the area covered by the seal in relation to the segment size. An automatically detected threshold value for each track was used to distinguish between fractal peaks and minor oscillations. Finally, the characteristics of each peak were determined, including the ARS duration and search area (see Tremblay et al. 2007 for more details). An index of search intensity (area peak) was calculated based on both time in ARS and distance covered. An index of track sinuosity was determined based on mean fractal D for each ARS period. Because ARS zones can include one or more bouts, these zones were compared based on the dominant strategy that was used during the ARS period.

Statistical analysis. Summary data are reported as mean $\pm \mathrm{SE}$, unless otherwise noted. Statistical analysis was conducted using R (R Foundation; www.rproject. org). Bout classification and movement parameters were compared using linear mixed models. Random factors for the models included animal ID and foraging trip within each animal. Year was included as a fixed factor in the models. Sampling frequency ('fast' = $1 \mathrm{~s}$, 'slow' = $5 \mathrm{~s}$ ) was also included as a fixed factor to test the influence of sampling rate on dive data. The most appropriate model was chosen from a combination of all random and fixed factors based on the lowest Bayesian information criterion (BIC; Burnham \& Anderson 2002). Because data for path straightness, IDZ, and DI were proportion data that did not show a normal distribution after 
transformation, models were fitted using Markov Chain Monte Carlo (MCMC) simulations using the R2jags package (Smithson \& Verkuilen 2006). A total of 10000 iterations were used with a burn-in of 2000 . The mean and 95\% CIs were calculated for the random and fixed factors to determine differences between bout types. Ranges presented are the minimum and maximum of the female averages. Data that were non-normal were $\log _{10}$ or square-root transformed. All contrasts were considered significantly different at $\mathrm{p}<0.05$.

\section{RESULTS}

In 2007, 5 fur seals were instrumented with an Mk10-AF tag and 8 were instrumented with both an Mk10-AF and an Mk10-L tag. One seal lost the Mk10-L tag prior to recapture. In 2008, 7 seals were equipped with an Mk10-AF and 22 seals were equipped with both an Mk10-AF and an Mk10-L tag. In 2008, there was significant instrument loss and it was discovered at recapture that the tracking instruments had separated from the glue base. This resulted in recaptures of 12 seals with both Mk10-AF and Mk10-L tags, 6 seals with only Mk10-AF tags, 3 seals with only Mk10-L tags, and 8 seals with no tags. Of the 8 seals that did not retain their instruments, 4 were relocated with the VHF transmitter still attached. Because no markers were used to identify individuals, we were unable to determine whether seals with glue patches that were resighted on the rookery were individuals that lost all instruments or were previously recaptured seals.

For 1 seal that was recaptured with only an Mk10-L (2008), no GPS data were transmitted and the dive data were therefore excluded from this analysis. An additional seal from 2008 was removed from the analysis as an outlier: she made 2 trips that were $>19 \mathrm{~d}$, and because she was not seen with a pup at recapture, it was presumed that she lost her pup. Although the Mk10-AF instruments were programmed to transmit dive data, these data were received in a histogram format and therefore could not be used for the analysis of fine-scale behavior.

In total, 71 foraging trips with matching GPS and dive data were obtained from 32 ind. At instrumentation, mean fur seal mass was $39.3 \pm 0.6 \mathrm{~kg}$, and females gained an average of $1.1 \pm 0.7 \mathrm{~kg}$ over the tracking period $(24.3 \pm 2.8 \mathrm{~d})$. In cases where duplicate dive data was acquired from an individual (both Mk10-AF and Mk10-L instruments), the highest resolution data was used for analysis (1 s sampling rate). As a result, dive data were analyzed from 21 Mk10-L tags (2007: 7 , 2008: 14) and $11 \mathrm{Mk10-AF} \mathrm{tags} \mathrm{(2007:} \mathrm{6,} \mathrm{2008:} \mathrm{5).}$

\section{Dive data}

Average BEC was $31.1 \pm 0.5$ min with a range of 21.7 to $41.2 \mathrm{~min}$; if a subsequent dive did not occur within this amount of time, a dive bout was considered over. On average, $14.7 \pm 0.9$ bouts were recorded per trip (range: $6-25$ ) and these bouts lasted for $5.4 \pm 0.1 \mathrm{~h}$. Cluster analysis of the dive bouts resulted in 3 distinct groups of dive behavior that were classified as epipelagic bouts $(n=613)$, benthic bouts $(n=212)$, and mixed dive bouts ( $\mathrm{n}=27$; Fig. 2). Visual examination of the mixed group showed that these dive bouts began as either epipelagic or benthic and then switched part way through (Fig. 2). Therefore, these mixed dive bouts were not included in subsequent analysis. Six females each displayed only 1 foraging strategy (100\% epipelagic, $\mathrm{n}=5 ; 100 \%$ benthic, $\mathrm{n}=1$ ), whereas the rest showed some combination of the two, both within and among trips (average proportion of epipelagic bouts for each female: $0.79 \pm 0.02$ ). After selecting bouts that met the minimum GPS location criterion, 412 bouts remained for the analysis of movement patterns (342 epipelagic bouts, 70 benthic bouts).

All of the dive parameters were significantly different between epipelagic and benthic bouts except for bottom time and the number of wiggles in the bottom phase (Table 1); for all parameters there was an effect of one or more of the random variables examined (Table 2). During benthic bouts, dives were over $3 \times$ deeper, nearly $2 \times$ longer, and had longer post-dive surface intervals than during epipelagic bouts (Table 1). Dive efficiency in epipelagic bouts was also $3 \times$ higher than in benthic bouts. Although the number of wiggles per dive did not differ, females covered a greater overall bottom range during the bottom phase of epipelagic bouts (Table 1). A detectable effect was found for both foraging trip and animal ID for dive depth, duration, bottom time, post-dive interval, wiggles in the bottom phase, dive efficiency, and dives per bout (Table 2). Animal ID showed a measurable effect for total vertical distance and foraging trip showed an effect for bottom range (Table 2). Sampling rate showed a detectable effect for the number of dive wiggles and the total vertical distance. Year was not a significant factor for any of the dive variables examined.

The IDZ of $51 \%$ (Table 1) that was obtained for epipelagic bouts was indicative of extensive variation in dive depths, consistent with fur seals tracking the movement of vertically migrating prey (Kooyman \& Goebel 1986, Goebel 1998). In contrast, benthic bouts had significantly higher IDZ (77\%; Table 1), showing a high association in dive depth between sequential dives. The differences between DIs show an even stronger distinction between the 2 bout types, with epipelagic bout mean values being only $0.28 \pm 0.01$ 

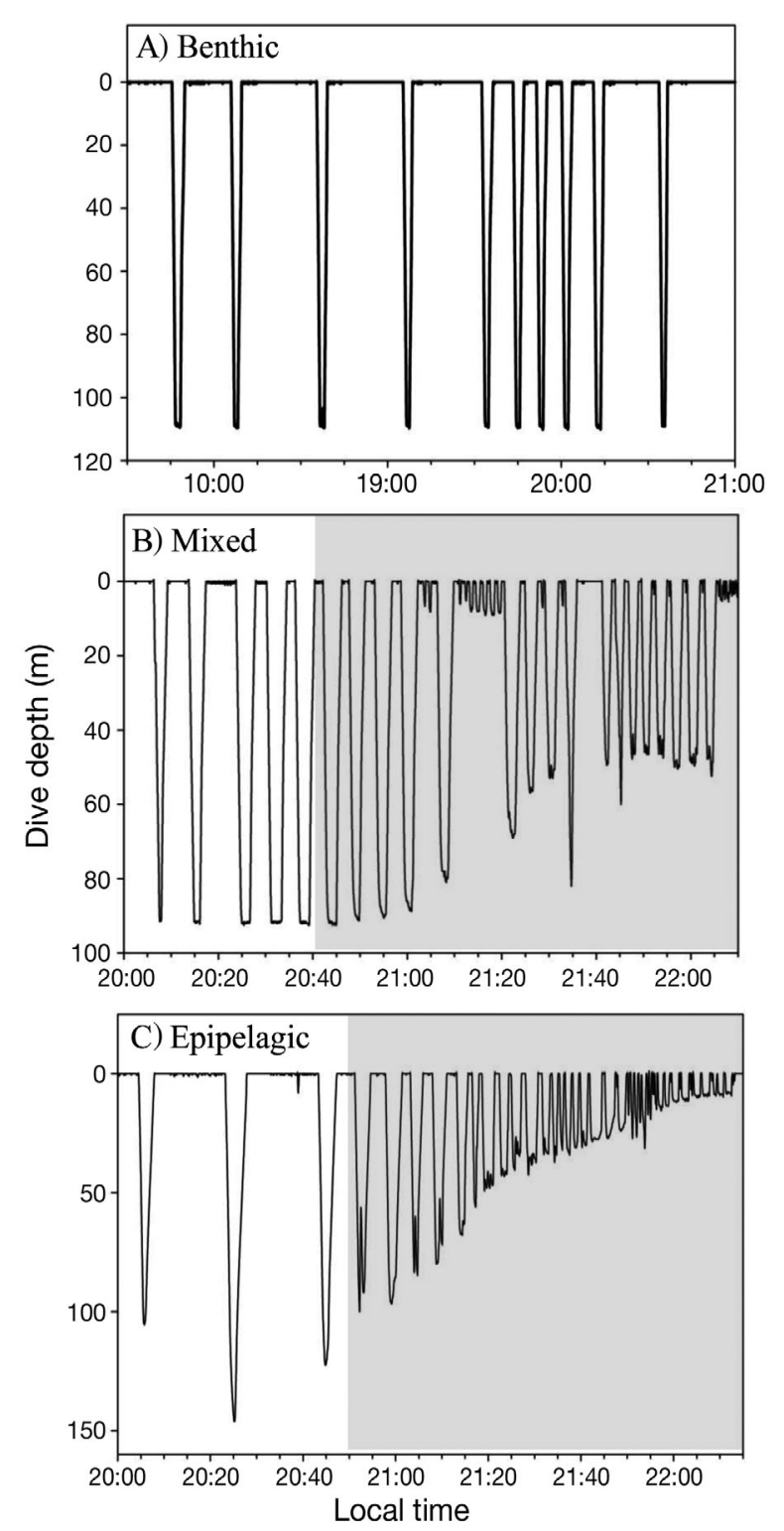

Fig. 2. Callorhinus ursinus. Examples of the 3 foraging strategies that were observed in distinct dive bouts. (A) Benthic diving was identified by repeated dives to the same depth, usually occurring during daylight hours. This is supported by the high dive index (DI) of 0.80 observed for this bout, which means dive depths were close to the ocean floor at this location. (B) Mixed diving was identified by a switch in diving strategy during a single bout. The mixed diving strategy occurred in $<4 \%$ of all bouts. The switch regularly occurred just after sunset (shaded area). The average DI for mixed dive bouts was $0.47 \pm 0.03$, which was midway between the DI for benthic and epipelagic dive bouts (see Table 1). (C) Epipelagic dive bouts were identified by shallow diving that had distinct variation in dive depths as measured by a lower intra-depth zone index (IDZ; see Table 2). This epipelagic dive bout began just prior to sunset (shaded area) and had a DI of 0.28 , indicating that the dives were not near the ocean floor. Note the decreasing trend in dive depth just after sunset, which likely resulted from this female tracking prey as it vertically ascended with decreasing light levels and benthic bout mean values being significantly higher at $0.83 \pm 0.02$ (Table 1 ). As was found with the previously described dive parameters, DI showed a detectable effect of animal ID, whereas IDZ showed an effect of year (Table 3). Finally, nearly equal numbers of epipelagic bouts occurred during the day and at night (45 and $55 \%$, respectively), whereas $78.6 \%$ of the benthic bouts began during the daytime hours.

\section{Tracking data}

Archived GPS tracks were acquired from 30 females (68 foraging trips), and transmitted GPS tracks (GPS-t) were used for the remaining 2 females (3 foraging trips). A total of 14169 GPS locations were acquired and 13488 remained after filtering (Fig. 1). This resulted in $192.2 \pm 13.5$ locations trip $^{-1}$ and $26.9 \pm$ 1.8 locations $\mathrm{d}^{-1}$ at sea. The average time between GPS locations was $1.3 \pm 0.1 \mathrm{~h}$, with an average maximum for all females of $10.6 \pm 1.1 \mathrm{~h}$ between locations. Although GPS-t data are generally acquired at a lower frequency than archived GPS data (Kuhn et al. 2009), removing bouts with <4 GPS locations rendered the temporal resolution of the GPS-t data (average time between locations: $1.6 \pm 0.04 \mathrm{~h}$ ) within the range acquired by archived GPS data.

Trip duration averaged $7.4 \pm 0.2 \mathrm{~d}$ and ranged from 3.7 to $11.4 \mathrm{~d}$. Trip durations were significantly shorter in 2008, and there was a detectable effect of individual (difference estimate $=-1.7, \mathrm{SE}=0.61, Z=-2.8$; animal ID: variance $=1.9, \mathrm{SD}=1.4$ ). These foraging trips covered areas around St. Paul Island that were within the $50 \mathrm{~m}$ depth contour to off-shelf regions over $1000 \mathrm{~m}$ deep (Fig. 1).

Females travelled almost $2 \times$ farther during epipelagic bouts than during benthic bouts (Tables $1 \& 2$ ); however, epipelagic bouts were over $2 \times$ longer in duration (Table 1). When transit rates during a bout were compared, the difference was not significant. Both foraging strategies had high straightness indices; nevertheless, seals travelled in a slightly straighter path during benthic foraging (Table 1, Fig. 3). For all movement parameters except path straightness, there was a detectable effect of one or more of the random factors (Tables $2 \& 3$ ).

The number of ARS periods detected was low, averaging $1.3 \pm 0.1$ per foraging trip; during 14 trips, no ARS zones were detected $\left(n=74\right.$, range: 0 to 3 trip $^{-1}$; Fig. 4). Time in ARS zones had a wide range of 0.08 to $3.3 \mathrm{~d}$ and females travelled an average of $36.8 \pm 3.1 \mathrm{~km}$ while in these ARS zones (range: 5.8 to $128.5 \mathrm{~km}$; Table 4). Sixty-five ARS periods were identified with predominantly epipelagic bouts and 8 with predominantly benthic bouts. An additional ARS period had no 
Table 1. Callorhinus ursinus. Average $( \pm \mathrm{SE})$ dive and movement parameters for each foraging strategy. Comparisons were made between the 2 foraging strategies using a linear mixed model or Markov Chain Monte Carlo (MCMC) simulations (path straightness, IDZ and DI, see 'Materials and methods' for details). Parameters with CIs that do not include 0 denote significant differences $\left({ }^{*}\right)$. For calculation of dive and movement parameters see 'Materials and methods'

\begin{tabular}{|c|c|c|c|}
\hline Parameters & Epipelagic & Benthic & $95 \% \mathrm{CI}$ \\
\hline Dive depth $(m)^{a}$ & $22.0(0.62)$ & $85.4(2.92)$ & $-0.58,-0.48^{*}$ \\
\hline Dive duration $(\mathrm{s})^{\mathrm{a}}$ & $97.7(1.99)$ & $187.5(4.01)$ & $-0.30,-0.22^{*}$ \\
\hline Bottom time $(\mathrm{s})^{\mathrm{a}}$ & $49.9(1.23)$ & $54.9(2.13)$ & $-0.09,0.02$ \\
\hline Post-dive interval (s) ${ }^{\mathrm{a}}$ & $100.5(5.0)$ & $768.8(68.8)$ & $-1.4,-1.8^{*}$ \\
\hline Wiggles in bottom phase ${ }^{a}$ & $4.7(0.14)$ & $5.9(.036)$ & $-0.03,0.05$ \\
\hline Total vertical distance $(\mathrm{m})^{\mathrm{a}}$ & $7.7(0.23)$ & $6.7(0.39)$ & $0.04,0.15^{*}$ \\
\hline Bottom range $(\mathrm{m})^{\mathrm{a}}$ & $3.0(0.070)$ & $2.9(0.24)$ & $0.02,0.13^{*}$ \\
\hline Dive efficiency ${ }^{\mathrm{a}}$ & $0.32(0.0058)$ & $0.10(0.0096)$ & $0.16,0.22^{*}$ \\
\hline Dives per bout & $201.0(8.0)$ & $21.8(2.5)$ & $5.9,8.7^{*}$ \\
\hline Intra-depth zone index (IDZ) & $0.51(0.01)$ & $0.77(0.02)$ & $0.8,1.4^{*}$ \\
\hline Dive index (DI) & $0.28(0.01)$ & $0.83(0.02)$ & $1.3,2.1^{*}$ \\
\hline Bout duration (h) & $8.2(0.2)$ & $3.8(0.3)$ & $0.24,0.38^{*}$ \\
\hline Total distance traveled (km) & $31.4(1.1)$ & $15.8(1.3)$ & $0.78,1.68^{*}$ \\
\hline Transit rate $\left(\mathrm{km} \mathrm{h}^{-1}\right)$ & $4.02(0.10)$ & $4.26(0.27)$ & $-0.22,0.06$ \\
\hline Straightness & $0.82(0.012)$ & $0.93(0.013)$ & $0.1,0.7^{*}$ \\
\hline
\end{tabular}

bouts that matched our diving criteria although diving occurred. There were no significant differences for the number of bouts between epipelagic and benthic ARS periods $\left(F_{1,71}=2.2, \mathrm{p}=0.14\right.$; Table 4$)$. In addition, there were no significant differences for many of the ARS period characteristics measured (duration: $F_{1,71}=$ $0.006, \mathrm{p}=0.93$; area of circle: $F_{1,84}=0.002, \mathrm{p}=0.89$; area peak: $F_{1,84}=0.07, \mathrm{p}=0.40$ ). However, epipelagic ARS periods had a significantly higher track sinuosity (mean fractal D: $F_{2,70}=3.9, \mathrm{p}=0.02$ ) and there was an effect of year, with the trend of 2008 being higher than that of 2007 ( $p=0.05)$.

\section{DISCUSSION}

\section{Dive behavior}

Cluster analysis of the dive behavior of northern fur seals revealed flexibility in foraging strategies within the St. Paul Island population. Although 3 strategies were identified, $>96 \%$ of the bouts were characterized as epipelagic or benthic diving and most females employed both of these strategies within a foraging trip. Although flexibility in foraging behavior was observed, foraging predominantly occurred in the epipelagic zone ( $>75 \%$ of all bouts). The ability to alternate between foraging strategies is not unique to northern fur seals and has been demonstrated in a variety of marine predators, including seabirds (Croxall et al. 1988, Tremblay \& Cherel 2000), marine mammals (Mattlin et al. 1998, Burns et al. 2004), and sea turtles (Hawkes et al. 2006). In some species, these changes are a response to aging/growth or seasonal variation. For example, loggerhead turtles Caretta caretta show a transition from epipelagic to benthic foraging with increased age (Hawkes et al. 2006, Hatase et al. 2007). Seasonal changes from summer epipelagic foraging to winter benthic foraging were also documented in New Zealand fur seals Arctocephalus fosteri (Mattlin et al. 1998) and crabeater seals Lobodon carcinophagus (Burns et al. 2004). The change in behavior for the New Zealand fur seals was a result of targeting different prey species, whereas Burns et al. (2004) suggested that crabeater seals were following the movements of a single prey species, krill Euphausia superba, toward the seafloor in winter.

For a limited number of marine species, flexibility in foraging behavior within a single trip has also been described. Both rockhopper Eudyptes chrysocome filholi and gentoo penguins show periods of epipelagic and benthic diving within a foraging trip, and the proportion of each strategy varied among individuals (Croxall et al. 1988, Tremblay \& Cherel 2000). As in New Zealand fur seals, the shift in foraging strategy for gentoo penguins was likely a result of transitioning from shallow-water, vertically migrating prey to benthic fish species (Croxall et al. 1988). The flexible behavior of northern fur seals may result from a shift in the targeted age class of the primary prey species, and/or targeting different prey species all together.

On St. Paul Island, the primary prey for adult female fur seals is walleye pollock Theragra chalcogramma, although other epipelagic and benthic prey 
Table 2. Callorhinus ursinus. Linear mixed model comparisons for dive and movement parameters. For each selected model, both the fixed and random effects results are presented. ID is a unique value for each tracked animal and TripID refers to each foraging trip. Year and dive sampling rate (fast $=1 \mathrm{~s}$, slow $=5 \mathrm{~s}$ ) were tested as a fixed effect for all models

\begin{tabular}{|c|c|c|c|c|c|c|c|}
\hline & \multicolumn{3}{|c|}{- Fixed effect -} & \multicolumn{4}{|c|}{ Random effect } \\
\hline & Estimate & $\mathrm{SE}$ & $Z$ & Variance & $\mathrm{SD}$ & Variance & $\mathrm{SD}$ \\
\hline \multicolumn{8}{|l|}{ Dive depth $(\log , \mathrm{m})$} \\
\hline Benthic & 1.81 & 0.040 & 45.3 & 0.012 & 0.11 & 0.022 & 0.15 \\
\hline Epipelagic & -0.53 & 0.027 & -19.8 & & & & \\
\hline \multicolumn{8}{|c|}{ Dive duration $(\log , s)$} \\
\hline Benthic & 2.21 & 0.030 & 70.4 & 0.0081 & 0.090 & 0.014 & 0.12 \\
\hline Epipelagic & -0.26 & 0.021 & -12.2 & & & & \\
\hline \multicolumn{8}{|l|}{ Bottom time $(\log , s)$} \\
\hline Benthic & 1.63 & 0.041 & 40.4 & 0.012 & 0.11 & 0.019 & 0.14 \\
\hline Epipelagic & -0.036 & 0.030 & -1.2 & & & & \\
\hline \multicolumn{8}{|c|}{ Post-dive interval $(\log , s)$} \\
\hline Benthic & 6.0 & 0.12 & 50.2 & 0.080 & 0.28 & 0.16 & 0.40 \\
\hline Epipelagic & -1.6 & 0.091 & -17.5 & & & & \\
\hline \multicolumn{8}{|c|}{ Wiggles in bottom phase $(\log )$} \\
\hline Benthic & 0.41 & 0.04 & 9.7 & 0.0038 & 0.061 & 0.018 & 0.13 \\
\hline Epipelagic & 0.009 & 0.021 & 0.4 & & & & \\
\hline Fast sampling rate & 0.31 & 0.055 & 5.7 & & & & \\
\hline \multicolumn{8}{|c|}{ Total vertical distance $(\log , \mathrm{m})$} \\
\hline Benthic & 0.65 & 0.039 & 17.0 & & & 0.018 & 0.14 \\
\hline Epipelagic & 0.096 & 0.029 & 3.3 & & & & \\
\hline Fast sampling rate & 0.17 & 0.038 & 4.4 & & & & \\
\hline \multicolumn{8}{|c|}{ Bottom range $(\log , \mathrm{m})$} \\
\hline Benthic & 0.37 & 0.030 & 12.7 & 0.012 & 0.11 & & \\
\hline Epipelagic & 0.073 & 0.029 & 2.5 & & & & \\
\hline \multicolumn{8}{|l|}{ Dive efficiency } \\
\hline Benthic & 0.11 & 0.018 & 6.3 & 0.0022 & 0.047 & 0.0037 & 0.061 \\
\hline Epipelagic & 0.19 & 0.014 & 14.1 & & & & \\
\hline \multicolumn{8}{|l|}{ Dives per bout (sqrt) } \\
\hline Benthic & 6.3 & 0.79 & 1.8 & 3.4 & 1.8 & 4.2 & 2.1 \\
\hline Epipelagic & 7.3 & 0.69 & 10.7 & & & & \\
\hline \multicolumn{8}{|c|}{ Bout duration $(\log , \mathrm{h})$} \\
\hline Benthic & -0.83 & 0.035 & -23.7 & 0.009 & 0.09 & & \\
\hline Epipelagic & 0.31 & 0.036 & 8.5 & & & & \\
\hline \multicolumn{8}{|c|}{ Total distance (sqrt, km) } \\
\hline Benthic & 4.18 & 0.25 & 16.8 & & & 0.44 & 0.67 \\
\hline Epipelagic & 1.23 & 0.23 & 5.4 & & & & \\
\hline \multicolumn{8}{|c|}{ Transit rate (sqrt, $\mathbf{k m ~ h}^{-1}$ ) } \\
\hline Benthic & 1.36 & 0.07 & 20.4 & 0.032 & 0.18 & 0.20 & 0.44 \\
\hline Epipelagic & -0.08 & 0.069 & -1.1 & & & & \\
\hline
\end{tabular}

Table 3. Callorhinus ursinus. Results of Markov Chain Monte Carlo (MCMC) comparisons for dive and movement parameters. Comparisons were made between epipelagic and benthic dive bouts, and both fixed and random effects were included. ID is a unique value for each tracked animal and TripID refers to each foraging trip. In addition, year was tested as a fixed effect. Parameters with CIs that do not include 0 denote significant differences $\left({ }^{*}\right)$

\begin{tabular}{|c|c|c|c|c|c|c|c|c|c|c|c|c|}
\hline & \multicolumn{3}{|c|}{ Type } & \multicolumn{3}{|c|}{- Year $\_$} & \multicolumn{3}{|c|}{$\longrightarrow$ ID -} & \multirow[b]{2}{*}{ Mean } & \multicolumn{2}{|c|}{ - TripID } \\
\hline & Mean & $\mathrm{SD}$ & $95 \% \mathrm{CI}$ & Mean & $\mathrm{SD}$ & $95 \%$ CI & Mean & $\mathrm{SD}$ & $95 \%$ CI & & $\mathrm{SD}$ & $95 \% \mathrm{CI}$ \\
\hline Intra-depth zone index (IDZ) & 1.07 & 0.16 & $0.8,1.4^{*}$ & 0.38 & 0.19 & $0.02,0.8^{*}$ & 0.076 & 0.059 & $0.0,0.2$ & 0.073 & 0.054 & $0.0,0.2$ \\
\hline Dive index (DI) & 1.7 & 0.18 & $1.3,2.1^{*}$ & -0.04 & 0.24 & $-0.5,0.4$ & 0.37 & 0.11 & $0.2,0.6^{*}$ & 0.09 & 0.07 & $0.0,0.3$ \\
\hline Straightness & 0.34 & 0.16 & $0.1,0.7^{*}$ & -0.13 & 0.19 & $-0.5,0.3$ & 0.085 & 0.06 & $0.0,0.24$ & 0.065 & 0.05 & $0.0,0.18$ \\
\hline
\end{tabular}




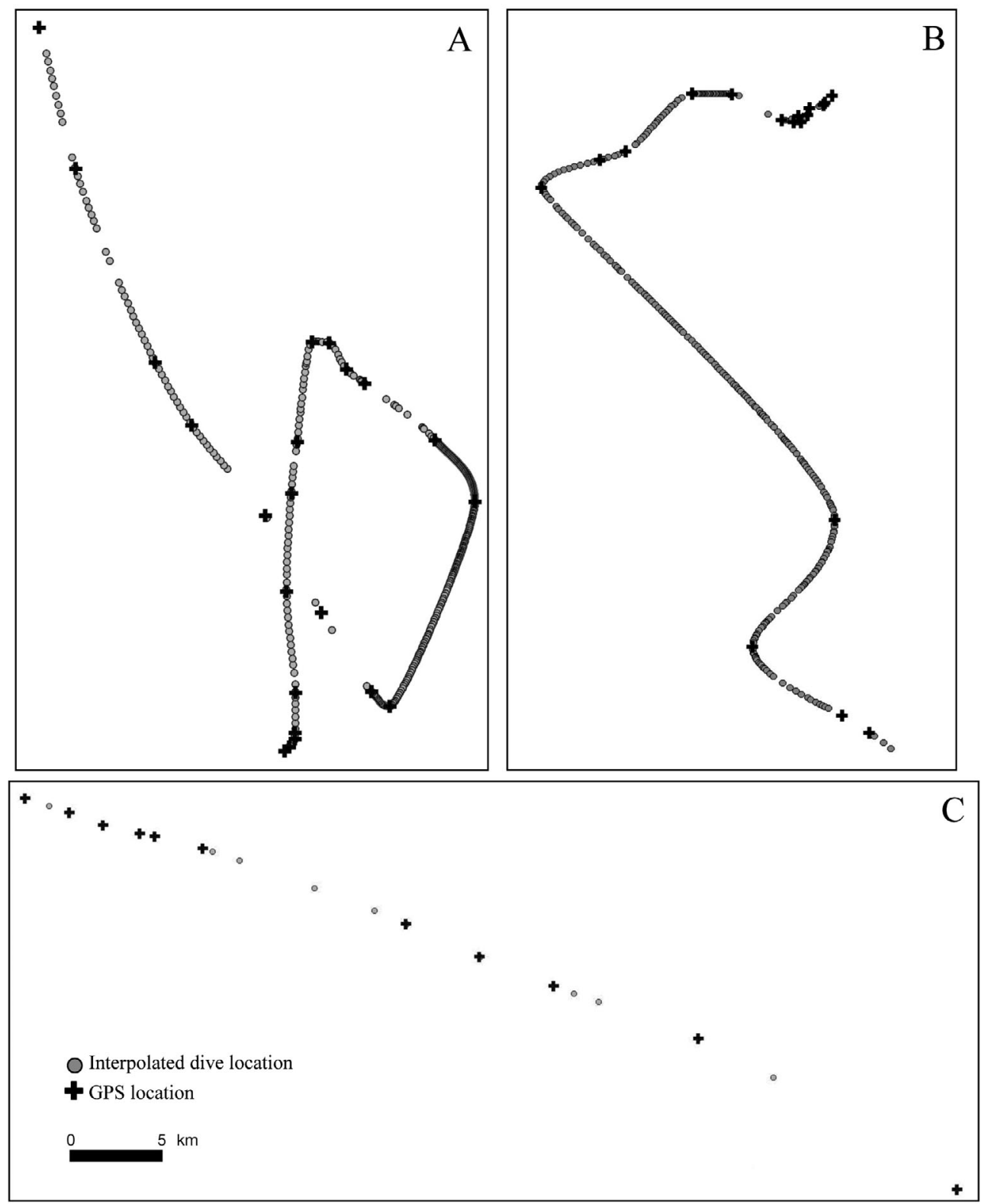

Fig. 3. Callorhinus ursinus. Examples of variation in path straightness for females displaying (A,B) epipelagic and (C) benthic dive bouts

species are also important (Antonelis et al. 1997, Gudmundson et al. 2006, Zeppelin \& Ream 2006). The proportion of the pollock in the diet varies among rookeries, ranging from 64 to $84 \%$ frequency of occurrence (Zeppelin \& Ream 2006). At the 2 rookeries used during this study, pollock frequency of occurrence was 66 and $64 \%$ (Vostochni and Reef, respectively; Zeppelin \& Ream 2006) and the next highest ranked species at both sites had just over $11 \%$ frequency of occurrence (Vostochni: Pacific sand lance Ammodytes hexapterus; Reef: squid, Gonatopsis borealis and/or Berryteuthis magister). Previous work has shown that in addition to differences in diet, females from these rookeries also tend to travel in different directions when foraging, resulting in habitat segregation between rookeries (Robson et al. 2004). Interestingly, although these patterns of habitat segregation appeared to be maintained by the females in this study, equal proportions of benthic and epipelagic dive bouts were recorded from females instrumented at each location (epipelagic bouts: Reef = 0.84 , Vostochni $=0.83$ ). This similarity in dive behavior may be due to the equally high proportions of pollock in the diet at each rookery. 


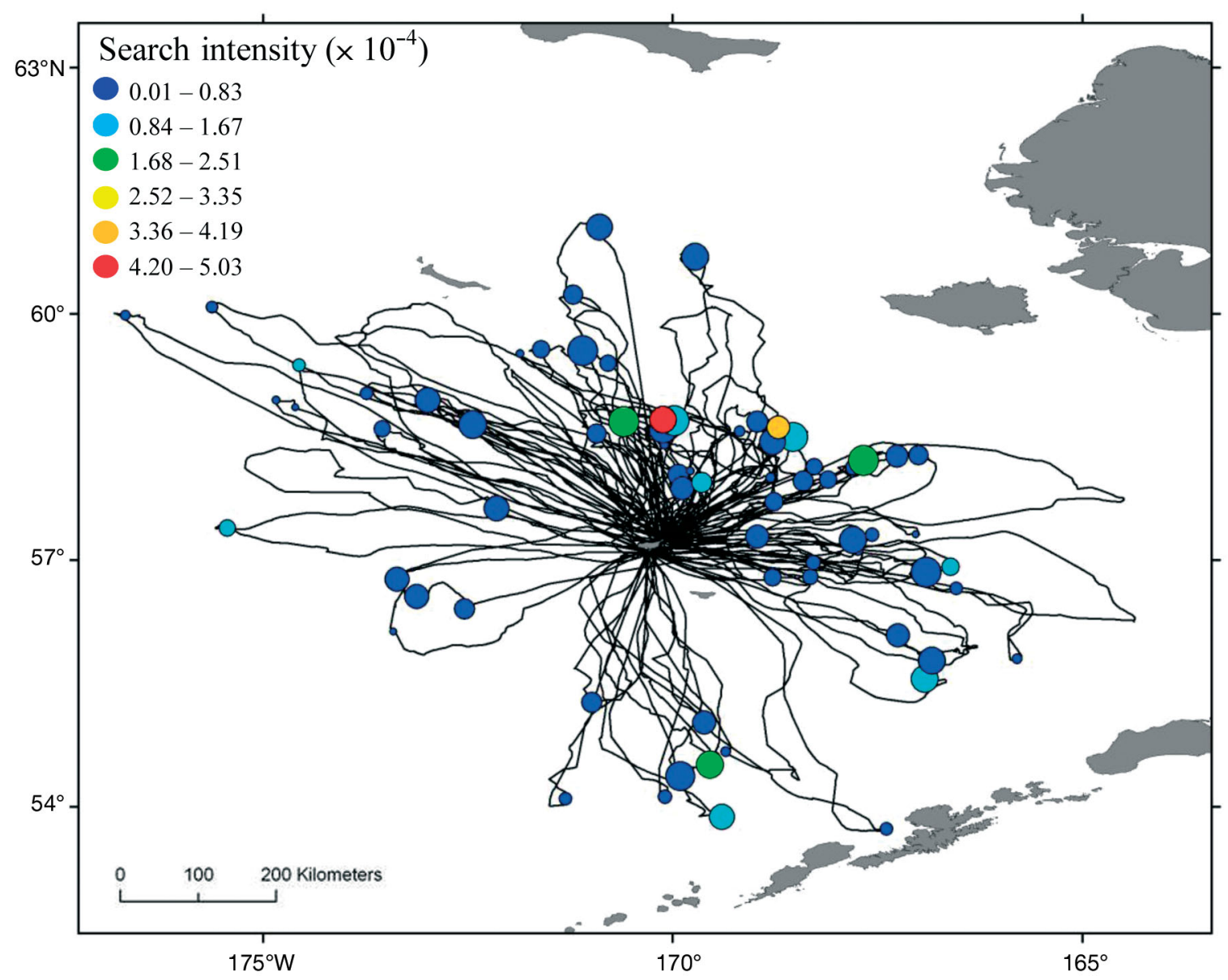

Fig. 4. Callorhinus ursinus. Foraging tracks (black lines) around St. Paul Island, AK, with periods of area-restricted search (ARS) behavior highlighted ( $\mathrm{n}=32$ females, 71 trips). The size of each circle represents the area of the circle containing the ARS period. Colors signify an index of the search intensity (see Tremblay et al. 2007 for more details). ARS periods occurred both along the foraging track and at the distal end and varied in both size and intensity throughout the foraging range

A combination of scat and regurgitate analyses from both rookeries showed that the age classes of pollock that were consumed ranged between 0 and 5 (or greater, Gudmundson et al. 2006). Because the vertical distribution and behavior of pollock vary with age (Bailey 1989), it may be possible to link fine-scale foraging behavior with the targeting of differing pollock age classes. For example, juvenile pollock tend to remain above the thermocline $(<40 \mathrm{~m})$ and migrate into shallow surface waters during the night as they follow vertically migrating zooplankton (Incze et al. 1988). This closely matches the shallow night diving that was observed in female fur seals during epipelagic bouts. Foraging on juvenile pollock could also explain the high percentage of epipelagic bouts during the day, as females may be targeting concentrated groups of fish at the thermocline. In contrast, adult pollock remain at or near the sea floor (Francis \& Bailey 1983, Bailey 1989), which would explain the deeper benthic diving.
At Vostochni rookery, Pacific sand lance is also an important prey species that uses both midwater and benthic habitats (Eschmeyer et al. 1983, Zeppelin \& Ream 2006), similar to pollock, which could also explain the alternative foraging strategies.

Future studies linking individual diet with at-sea behavior will be necessary to directly relate differences in fine-scale foraging behavior to prey selection in this species. A recent study of Antarctic fur seals Arctocephalus gazella found that the accuracy of foraging habitat models increased significantly when individual diet was incorporated in the models (Casper et al. 2010). For the declining northern fur seal population on St. Paul Island, a similar study integrating diet and fine-scale movements could aid in the interpretation of at-sea behavior and help define critical foraging habitat. In addition, by creating foraging habitat models that take into account rookery-level differences in diet, it may be possible to make unique predictions 
Table 4. Callorhinus ursinus. Average $( \pm \mathrm{SE})$ characteristics for northern fur seal area-restricted search (ARS) periods consisting primarily of epipelagic and benthic dive bouts. Because ARS zones included $>1$ bouts, these zones were classified based on the dominant foraging strategy used during each ARS period. Count: no. of bouts per ARS period, ranging from 0-9; Area above peak: sinuosity of the track within the ARS zone) was the only characteristic that was significantly different $\left({ }^{*}\right)$

\begin{tabular}{|lccc|}
\hline & $\begin{array}{c}\text { Epipelagic } \\
\text { bouts }\end{array}$ & $\begin{array}{c}\text { Benthic } \\
\text { bouts }\end{array}$ & $\begin{array}{c}\text { All ARS } \\
\text { periods }\end{array}$ \\
\hline Count & $2.0 \pm 0.16$ & $2.8 \pm 0.56$ & $2.1 \pm 0.15$ \\
Duration $(\mathrm{d})$ & $1.1 \pm 0.10$ & $1.0 \pm 0.19$ & $1.1 \pm 0.09$ \\
Area above peak $\left(\times 10^{-5}\right)$ & $5.8 \pm 1.1$ & $2.3 \pm 0.6$ & $5.4 \pm 1.0$ \\
Mean fractal $\mathrm{D}^{*}$ & $1.1 \pm 0.01$ & $1.0 \pm 0.02$ & $1.1 \pm 0.009$ \\
Area of circle $\left(\mathrm{km}^{2}\right)$ & $208.9 \pm 22.9$ & $206.6 \pm 50.1$ & $207.0 \pm 20.8$ \\
Dist. traveled in circle $(\mathrm{km})$ & $37.1 \pm 3.4$ & $35.1 \pm 7.1$ & $36.8 \pm 3.1$ \\
\hline
\end{tabular}
an index to measure ARS intensity (see Fig. 4). Mean fractal D (an index of the

fine-scale movements during these epipelagic bouts, including water and prey movement patterns. For example, various currents flow along the shelf domains and across the Bering shelf (Stabeno et al. 2001), which could impact the movement direction and speed of the foraging fur seals regardless of the type of foraging strategy being used. In addition, juvenile pollock can be persistent swimmers and are able to maintain swimming speeds of up to $2.5 \mathrm{~km} \mathrm{~h}^{-1}$ for $>3 \mathrm{~h}$ (Olla et al. 1997). If a school of juvenile pollock that is being targeted maintains a generally straight swimming path, this could also explain the high path straightness during epipelagic foraging bouts.

about how each rookery will be impacted by changes to the environment or prey resources, which could guide important conservation decisions.

\section{Movement patterns}

Although the dive behavior of northern fur seals has been described previously (Gentry et al. 1986, Goebel et al. 1991, Goebel 1998), this study was unique in that we were able to examine how space use varied between alternative foraging strategies by employing highly accurate GPS tracking technology. In contrast to the differences that were found in the dive data between epipelagic and benthic foraging bouts, only total distance traveled and path straightness were significantly different for movement patterns. However, the significantly higher total distance traveled can be explained by the longer bout durations during epipelagic foraging, since transit rates were not different between the 2 strategies. Therefore, the only remaining difference in movement patterns between the 2 foraging patterns was the difference in path straightness.

The overall straight nature of travel during both epipelagic and benthic bouts was surprising, as we expected females to concentrate their fine-scale movements in areas of high prey density or recent prey capture (Kareiva \& Odell 1987, Fauchald \& Tveraa 2003). Yet, even with the high level of path straightness, the most sinuous tracks were identified during epipelagic bouts, which is consistent with encircling or following schools of patchy prey. Similar movements have also been described for basking sharks Cetorhinus maximus, whose swimming paths become more convoluted while feeding on high densities of patchy zooplankton (Sims \& Quayle 1998). It is also important to keep in mind that other factors, both physical and biological, may influence
In contrast, the high level of path straightness during benthic dive bouts might have resulted from the seals hunting single large adult pollock; hence, concentrating movements in a small area might not be as effective. In fact, studies using underwater cameras on both monk Monachus schauinslandi and harbor seals Phoca vitulina found that animals tend to cruise rapidly along the bottom instead of focusing their efforts in a single area (Bowen et al. 2002, Parrish et al. 2000). For harbor seals, this type of movement occurred most often when densities of cryptic bottom prey were low (Bowen et al. 2002). Parrish et al. (2000) proposed that this rapid movement along the bottom was a method to minimize the amount of time prey had to detect the seal, and could result in increased foraging success.

Another possible explanation for the higher path straightness during benthic foraging could be related to the increased surface intervals that were observed with benthic diving. These increased surface intervals may be required to recover from the longer dive durations or could be periods when the seal is handling and consuming the larger adult pollock. The increased time at the surface along with the travel time to and from the sea floor may give benthic prey a chance to move or disperse, which would require the seal to transit to locate more prey. In contrast, the short surface intervals and shallow depths of epipelagic dives mean that the seal could maintain contact with the school of prey during the entire foraging bout.

\section{Area-restricted search behavior}

When foraging in areas with patchily distributed resources, predators can increase foraging success by modifying movements in response to prey encounters (Kareiva \& Odell 1987, Fauchald \& Tveraa 2003). 
These modifications lead to ARS patterns that are often characterized by decreased transit rates and increased turning rates. Due to the patchy distribution of prey in the marine environment, multiple studies have used ARS behavior to identify foraging periods and locate important foraging habitat of marine predators (Weimerskirch et al. 2008, Weng et al. 2008, Bailey et al. 2009). For example, using ARS locations, a recent study identified the North Pacific Transition Zone as an important foraging area for Laysan albatross Phoebastria immutabilis (Tremblay et al. 2007). Bailey \& Thompson (2006) used similar indices of increased search effort (first-passage time) to identify potential foraging sites for bottlenose dolphins Tursiops truncatus. These authors found that visually identified foraging behaviors (e.g. fish tossing) were more likely to occur in areas with the highest search effort.

As central place foragers during the breeding season, female fur seals focus foraging efforts on the areas surrounding St. Paul Island (Robson et al. 2004), and as expected, ARS behavior was found throughout this region. However, only a few ARS periods were identified per trip and these were generally low in overall intensity. The limited or low intensity ARS periods that were observed in the present study could result from a variety of factors including uniformly distributed prey, low density prey patches, or decreased ability to locate prey patches. For example, if pollock were evenly distributed within the foraging habitat, then foraging success would increase with distance covered, leading to more straight than sinuous paths (Krakauer \& Rodríguez-Gironés 1995, Austin et al. 2004, Scharf et al. 2009). Using simulation modeling, Scharf et al. (2009) showed that after prey were encountered, searching was more directional when resources were regularly distributed. However, studies of pollock distribution in the Bering Sea do not support the hypothesis that this species is uniformly distributed (Wespestad et al. 2000); hence this does not explain the low number of ARS zones detected.

If prey patches were of poor quality (i.e. fewer or smaller prey), females should also show more longdistance movements with low turning frequency while searching for new prey patches, leading to minimal time in ARS behavior (Zach \& Falls 1976, Fauchald 1999, Nolet \& Mooij 2002). Similarly, if females were struggling to find prey resources in general, then there would also be a lack of ARS periods along the tracks. For example, female northern elephant seals spent proportionally more time in directed transit during years of low prey availability (Crocker et al. 2006). However, on average, the fur seals tracked in this study gained mass over the tracking period while continuing to nurse a young pup, suggesting that both of these hypotheses are not supported. In 2007, we found some evidence that females had difficulty locating prey resources, as trip durations were significantly longer and females travelled greater distances from the rookery (Kuhn et al. 2009). Nevertheless, these differences in at-sea movements did not result in differences in ARS characteristics between years. Thus, there may be another explanation for the lack of ARS periods identified for female northern fur seals, including the possibility that ARS analysis does not reliably identify foraging effort in this species.

This lack of association between ARS periods and foraging effort may also explain why there were no differences in the characteristics of epipelagic and benthic ARS periods. One potential limitation could be the method used to categorize ARS periods, as each ARS period included one or more bouts and many also included extended periods between dive bouts. The lack of association between ARS behavior and foraging was also observed in the wandering albatross Diomedea exulans, where researchers showed that prey capture usually did not result in increased track sinuosity (Weimerskirch et al. 2007). ARS periods with little or no bout diving were also identified, further supporting the conclusion that ARS analysis may not be the most appropriate method to describe the at-sea movements of, or identify key foraging areas for, northern fur seals during the breeding season. This could result from the generally straight nature of fur seal travel or the extensive time this species spends in resting and grooming at the surface (Insley et al. 2008). These resting and grooming periods result in increased residence time in an area, which may mistakenly be identified as ARS behavior.

Finally, it is important to consider the resolution of the tracking data in relation to both the temporal and spatial scale of ARS patterns. The GPS locations in this study were obtained at a rate of just over 1 location $\mathrm{h}^{-1}$, with an average distance between locations of $\sim 4 \mathrm{~km}$ (Kuhn et al. 2009). If the ARS behavior of northern fur seals occurred on shorter temporal or smaller spatial scales, it would be impossible to detect using this dataset. This was the case for both masked boobies Sula dactylatra and bottlenose dolphins where increased sampling rate or visual observations allowed the identification of ARS zones that were $<4 \mathrm{~km}$ (Bailey \& Thompson 2006, Weimerskirch et al. 2008). An additional study using GPS tracking with a higher sampling rate is one way to determine whether northern fur seals in fact show ARS behavior on a much smaller scale.

\section{Ecological implications}

While GPS tracking has provided a greater understanding of the fine-scale movements of the northern 
fur seal, GPS technology can also be used to gain insight into prey distributions and the impacts of environmental change. When comparing the findings of this study to previous tracking studies, it appears that the foraging ranges of female northern fur seals breeding on St. Paul are generally fixed around the island (Robson et al. 2004, Call et al. 2008). Therefore, differences in use patterns among years within this larger foraging range could provide insight into changes in prey distribution. For example, previous studies in other marine species have shown that locations of increased foraging effort are directly linked to high prey abundance in an area (e.g. Guinet et al. 2001). Additionally, changes in bout diving characteristics could be used to understand changes in prey abundance (Harcourt et al. 2002, Mori \& Boyd 2004, Austin et al. 2006). Mori \& Boyd (2004) showed that both bout length and time between bouts were correlated with krill abundance in foraging Antarctic fur seals. In fact, these authors suggested that examining changes in fur seal behavior has advantages over traditional hydroacoustic surveys for estimating krill abundance. In northern fur seals, because females have a variety of foraging options (benthic, epipelagic, or mixed), changes in the proportion of each foraging strategy used may also provide insight into changes in prey resources. In Weddell seals Leptonychotes weddellii, temporal changes in prey abundance were shown to impact the foraging strategy employed (either benthic or epipelagic), and it was suggested that seals would not switch to benthic foraging when prey were available in the water column (Plötz et al. 2001). Due to the increased challenges of benthic foraging (Costa \& Gales 2003), we also predict that female northern fur seals would only transition to benthic foraging when epipelagic resources in an area decline or are scarce.

Given that northern fur seals are currently listed as depleted and pup production on St. Paul Island has shown no changes from the recent pattern of decline (Towell et al. 2006, NMFS 2007), scientists and managers continue to search for causes. Among the list of potential concerns are changes in the foraging environment, depleted prey resources, and competition with the commercial fisheries that occur throughout the fur seal's foraging range (NMFS 2007, Hiatt et al. 2008). Consequently, the northern fur seal conservation plan listed among its highest-level priorities the tasks of describing essential fur seal foraging habitat and monitoring changes in foraging behavior and habitat use over time (NMFS 2007). The present study directly contributes to this conservation objective by linking dive behavior with fine-scale movement patterns to describe essential foraging habitat both geographically and within the water column. By monitoring fine-scale habitat use and at-sea behavior over time and making comparisons between St. Paul Island and other islands (including both stable and recovering islands), it may be possible to gain a greater understanding of the interactions between this species and local environmental conditions, fish resources, and commercial fisheries, all of which are essential for effective management and conservation.

In conclusion, the combination of highly accurate GPS locations with dive data resulted in the first description of fine-scale foraging behavior in this species, making it possible to examine whether movement patterns differ when fur seals employ alternative foraging strategies. Although northern fur seals appear to employ 2 distinct foraging strategies during the breeding season, the predominant use of epipelagic dive bouts suggests that this may be a more profitable foraging strategy. Interestingly, while dive characteristics were strikingly different between the 2 foraging strategies, most movement patterns were not significantly different. Future studies integrating analysis of finescale foraging behavior with data about individual diet and environmental conditions within the foraging habitat will be essential to add to our understanding of northern fur seal ecology, increase the effectiveness of conservation efforts, and aid in developing predictions about the impacts of environmental change on this depleted species.

Acknowledgements. This research was conducted under Marine Mammal Protection Act permit no. 782-1708-04. We thank J. Baker, K. Call, C. Dorr, B. Fadely, E. Kunisch, K. Sweeney, J. Thomason, R. Towell and T. Zeppelin for assistance with field research and logistical support. Veterinary support was provided by D. DeGhetto and F. Nutter. D. Johnson supplied valuable statistical support and H. MostmanLiwanag, A. Orr, and P. Robinson offered helpful comments on previous drafts. This research was performed while C.E.K. held a National Research Council Research Associateship Award at the Alaska Fisheries Science Center's National Marine Mammal Laboratory. Reference to trade names does not imply endorsement by the National Marine Fisheries Service, NOAA.

\section{LITERATURE CITED}

Antonelis GA, Sinclair EH, Ream RR, Robson BW (1997) Interisland variation in the diet of female northern fur seals (Callorhinus ursinus) in the Bering Sea. J Zool 242: $435-451$

Argos (2006) Argos user's manual. CLS, Ramonville SaintAgne, available at www.argos-system.org/manual

Austin D, Bowen WD, McMillan JI (2004) Intraspecific variation in movement patterns: modeling individual behaviour in a large marine predator. Oikos 105:15-30

Austin D, Bowen WD, McMillan JI, Boness DJ (2006) Stomach temperature telemetry reveals temporal patterns of foraging success in a free-ranging marine mammal. J Anim Ecol 75:408-420 
Bailey KM (1989) Interaction between the vertical distribution of juvenile walleye pollock Theragra chalcogramma in the eastern Bering Sea, and cannibalism. Mar Ecol Prog Ser 53:205-213

Bailey H, Thompson P (2006) Quantitative analysis of bottlenose dolphin movement patterns and their relationship with foraging. J Anim Ecol 75:456-465

Bailey H, Mate BR, Palacios DM, Irvine L, Bograd SJ, Costa DP (2009) Behavioural estimation of blue whale movements in the Northeast Pacific from state-space model analysis of satellite tracks. Endang Species Res 10:93-106

Bowen WD, Tully D, Boness DJ, Bulheier BM, Marshall GJ (2002) Prey-dependent foraging tactics and prey profitability in a marine mammal. Mar Ecol Prog Ser 244: 235-245

Bradshaw CJA, Higgins J, Michael KJ, Wotherspoon SJ, Hindell MA (2004) At-sea distribution of female southern elephant seals relative to variation in ocean surface properties. J Mar Sci 61:1014-1027

Bryant E (2007) 2D location accuracy statistics for Fastloc ${ }^{\circledR}$ cores running firmware versions $2.2 \& 2.3$. Fastloc Technical Report TR01. Wildtrack Telemetry Systems, available at www.wildtracker.com

Burnham KP, Anderson DR (2002) Model selection and multimodel inference: a practical information-theoretic approach. Springer, New York, NY

> Burns JM, Costa DP, Fedak MA, Hindell MA and others (2004) Winter habitat use and foraging behavior of crabeater seals along the Western Antarctic Peninsula. Deep-Sea Res II 51:2279-2303

Call KA, Ream RR, Johnson D, Sterling JT, Towell RG (2008) Foraging route tactics and site fidelity of adult female northern fur seal (Callorhinus ursinus) around the Pribilof Islands. Deep-Sea Res II 55:1883-1896

Casper RM, Sumner MD, Hindell MA, Gales NJ, Staniland IJ, Goldsworthy SD (2010) The influence of diet on foraging habitat models: a case study using nursing Antarctic fur seals. Ecography. doi:10.1111/j.1600-0587.2009.06155.x

Costa DP, Gales NJ (2003) Energetics of a benthic diver: seasonal foraging ecology of the Australian sea lion, Neophoca cinerea. Ecol Monogr 73:27-43

> Crocker D, Costa DP, Le Boeuf BJ, Webb PM, Houser DS (2006) Impact of El Niño on the foraging behavior of northern elephant seals. Mar Ecol Prog Ser 309:1-10

> Croxall JP, Davis RW, O'Connell MJ (1988) Diving patterns in relation to diet of gentoo and macaroni penguins at South Georgia. Condor 90:157-167

Eschmeyer WN, Herald ES, Hammann H (1983) A field guide to Pacific coast fishes of North America. Houghton Mifflin Company, Boston, MA

Fauchald P (1999) Foraging in a hierarchical patch system. Am Nat 153:603-613

Fauchald P, Tveraa T (2003) Using first-passage time in the analysis of area-restricted search and habitat selection. Ecology 84:282-288

Francis RC, Bailey KM (1983) Factors affecting recruitment of selected gadoids in the northeast Pacific and east Bering Sea. In: Wooster WS (ed) From year to year. Washington Sea Grant, University of Washington, Seattle, WA, p 35-60

Gentry R, Kooyman GL (1986) Fur seals: maternal strategies on land and at sea. Princeton University Press, Princeton, NJ

Gentry RL, Kooyman GL, Goebel ME (1986) Feeding and diving behavior of northern fur seals. In: Gentry RL, Kooyman GL (eds) Fur seals: maternal strategies on land and at sea. Princeton University Press, Princeton, NJ

Georges JY, Tremblay Y, Guinet C (2000) Seasonal diving behaviour in lactating subantarctic fur seals on Amsterdam Island. Polar Biol 23:59-69

Goebel ME (1998) Female foraging behavior: inter- and intraannual variation in individuals. In: Gentry R (ed) Behavior and ecology of the northern fur seal. Princeton University Press, Princeton, NJ, p 243-259

Goebel ME, Bengtson JL, Delong RL, Gentry RL, Loughlin TR (1991) Diving patterns and foraging locations of female northern fur seal. Fish Bull 89:171-179

Gudmundson CJ, Zeppelin TK, Ream RR (2006) Application of two methods for determining diet of northern fur seals (Callorhinus ursinus). Fish Bull 104:445-455

Guinet C, Dubroca L, Lea MA, Goldsworthy S and others (2001) Spatial distribution of foraging in female Antarctic fur seals Arctocephalus gazella in relation to oceanographic variables: a scale-dependent approach using geographic information systems. Mar Ecol Prog Ser 219: 251-264

Harcourt RG, Bradshaw CJA, Dickson K, Davis LS (2002) Foraging ecology of a generalist predator, the female New Zealand fur seal. Mar Ecol Prog Ser 227:11-24

Hatase H, Omuta K, Tsukamoto K (2007) Bottom or midwater: alternative foraging behaviours in adult female loggerhead sea turtles. J Zool 273:46-55

Hawkes LA, Broderick AC, Coyne MS, Godfrey MH and others (2006) Phenotypically linked dichotomy in sea turtle foraging requires multiple conservation approaches. Curr Biol 16:990-995

Hays GC, Hobson VJ, Metcalfe JD, Righton D, Sims DW (2006) Flexible foraging movements of leatherback turtles across the Northern Atlantic Ocean. Ecology 87: 2647-2656

Hazel J (2009) Evaluation of fast-acquisition GPS in stationary tests and fine-scale tracking of green turtles. J Exp Mar Biol Ecol 374:58-68

Hiatt T, Felthoven R, Dalton M, Garber-Yonts B and others (2008) Stock assessment and fishery evaluation report for the ground fisheries of the Gulf of Alaska and Bering Sea/Aleutian Island Area: economic status of the groundfisheries off Alaska, 2007. Alaska Fisheries Science Center, National Marine Fisheries Service, Seattle, WA

- Hochscheid S, Godley BJ, Broderick AC, Wilson RP (1999) Reptilian diving: highly variable dive patterns in the green turtle, Chelonia mydas. Mar Ecol Prog Ser 185:101-112

Incze LS, Macgill Hynde C, Kim S, Strickland R (1988) Walleye pollock, Theragra chalcogramma, in the eastern Bering Sea. In: Wilimovsky NJ, Incze LS, Westrheim SJ (eds) Species synopses: life histories of selected fish and shellfish of the Northeast Pacific and Bering Sea. Washington Sea Grant Program and Fisheries Research Institute, University of Washington, Seattle, WA, p 55-69

Insley SJ, Robson BW, Yack T, Ream RR, Burgess WC (2008) Acoustic determination of activity and flipper stroke rate in foraging northern fur seal females. Endang Species Res $4: 147-155$

Jay CV, Garner GW (2002) Performance of a satellite-linked GPS on Pacific walruses (Odobenus rosmarus divergens). Polar Biol 25:235-237

Kareiva P, Odell G (1987) Swarms of predators exhibit 'preytaxis' if individual predators use area-restricted search. Am Nat 130:233-270

Kooyman GL, Goebel ME (1986) Feeding and diving behavior of northern fur seals. In: Gentry RL, Kooyman GL (eds) Maternal strategies on land and at sea. Princeton University Press, Princeton, NJ, p 61-78

Krakauer DC, Rodríguez-Gironés MA (1995) Searching and learning in a random environment. J Theor Biol 177: $417-429$ 
Kuhn CE, Johnson DS, Ream RR, Gelatt TS (2009) Advances in the tracking of marine species: using GPS locations to evaluate satellite track data and a continuous-time movement model. Mar Ecol Prog Ser 393:97-109

Le Boeuf BJ, Crocker DE, Costa DP, Blackwell SB, Webb PM, Houser DS (2000) Foraging ecology of northern elephant seals. Ecol Monogr 70:353-382

Mattern T, Ellenberg U, Houston DM, Davis LS (2007) Consistent foraging routes and benthic foraging behaviour in yellow-eyed penguins. Mar Ecol Prog Ser 343:295-306

> Mattlin RH, Gales NJ, Costa DP (1998) Seasonal dive behaviour of lactating New Zealand fur seals (Arctocephalus forsteri). Can J Zool 76:350-360

Mori Y, Boyd IL (2004) The behavioral basis for nonlinear functional responses and optimal foraging in Antarctic fur seals. Ecology 85:398-410

Naito Y, Asaga T, Ohyama Y (1990) Diving behavior of Adélie penguins determined by time-depth recorder. Condor 92 582-586

NMFS (2007) Conservation plan for the Eastern Pacific stock of northern fur seal (Callorhinus ursinus). National Marine Fisheries Service, Juneau, AK

$>$ Nolet BA, Mooij WM (2002) Search paths of swans foraging on spatially autocorrelated tubers. J Anim Ecol 71: 451-462

> Olla BL, Davis MW, Schreck CB (1997) Effects of simulated trawling on sablefish and walleye pollock: the role of light intensity, net velocity and towing duration. J Fish Biol 50: 1181-1194

> Parrish FA, Craig MP, Ragen TJ, Marshall GJ, Buhleier BM (2000) Identifying diurnal foraging habitat of endangered Hawaiian monk seals using a seal-mounted video camera. Mar Mamm Sci 16:392-412

Plötz J, Bornemann H, Knust R, Schröder A, Bester M (2001) Foraging behaviour of Weddell seals, and its ecological implications. Polar Biol 24:901-909

Ream RR, Sterling JT, Loughlin TR (2005) Oceanographic features related to northern fur seal migratory movements. Deep-Sea Res II 52:823-843

Robson BW, Goebel ME, Baker JD, Ream RR and others (2004) Separation of foraging habitat among breeding sites of a colonial marine predator, the northern fur seal (Callorhinus ursinus). Can J Zool 82:20-29

> Scharf I, Kotler B, Ovadia O (2009) Consequences of food distribution for optimal searching behavior: an evolutionary model. Evol Ecol 23:245-259

Schofield G, Bishop CM, MacLean G, Brown P and others (2007) Novel GPS tracking of sea turtles as a tool for conservation management. J Exp Mar Biol Ecol 347:58-68

Simmons SE, Crocker DE, Kudela RM, Costa DP (2007) Linking foraging behaviour of the northern elephant seal with oceanography and bathymetry at mesoscales. Mar Ecol Prog Ser 346:265-275

Sims DW, Quayle VA (1998) Selective foraging behaviour of basking sharks on zooplankton in a small-scale front. Nature 393:460-464

Sisak MM (1998) Animal-borne GPS and the deployment of a GPS based archiving datalogger on Hawaiian monk

Editorial responsibility: Jonathan Green,

Liverpool, UK seal (Monachus schauinslandi). Mar Technol Soc J 32: 30-36

Smithson M, Verkuilen J (2006) A better lemon squeezer? maximum-likelihood regression with beta-distributed dependent variables. Psychol Methods 11:54-71

Stabeno PJ, Bond NA, Kachel NB, Salo SA, Schumacher JD (2001) On the temporal variability of the physical environment over the south-eastern Bering Sea. Fish Oceanogr 10:81-98

Towell RG, Ream RR, York AE (2006) Decline in northern fur seal (Callorhinus ursinus) pup production on the Pribilof Islands. Mar Mamm Sci 22:486-491

Tremblay Y, Cherel Y (2000) Benthic and pelagic dives: a new foraging behaviour in rockhopper penguins. Mar Ecol Prog Ser 204:257-267

Tremblay Y, Cherel Y (2003) Geographic variation in the foraging behaviour, diet, and chick growth of rockhopper penguins. Mar Ecol Prog Ser 251:279-297

Tremblay Y, Shaffer SA, Fowler SL, Kuhn CE and others (2006) Interpolation of animal tracking data in a fluid environment. J Exp Biol 209:128-140

Tremblay Y, Roberts AJ, Costa D (2007) Fractal landscape method: an alternative approach to measuring arearestricted searching behavior. J Exp Biol 210:935-945

Villegas-Amtmann S, Costa DP, Tremblay Y, Salazar S, Aurioles-Gamboa D (2008) Multiple foraging strategies in a marine apex predator, the Galapagos sea lion Zalophus wollebaeki. Mar Ecol Prog Ser 363:299-309

Weimerskirch H, Bonadonna F, Bailleul F, Mabille G, Dell'Omo G, Lipp HP (2002) GPS tracking of foraging albatrosses. Science 295:1259

- Weimerskirch H, Pinaud D, Pawlowski F, Bost CA (2007) Does prey capture induce area-restricted search? A fine-scale study using GPS in a marine predator, the wandering albatross. Am Nat 170:734-743

Weimerskirch H, Le Corre M, Bost CA (2008) Foraging strategy of masked boobies from the largest colony in the world: relationship to environmental conditions and fisheries. Mar Ecol Prog Ser 362:291-302

Weng KC, Foley DG, Ganong JE, Perle C, Shillinger GL, Block BA (2008) Migration of an upper trophic level predator, the salmon shark Lamna ditropis, between distant ecoregions. Mar Ecol Prog Ser 372:253-264

Wespestad VG, Fritz LW, Ingraham WJ, Megrey BA (2000) On relationships between cannibalism, climate variability, physical transport, and recruitment success of Bering Sea walleye pollock (Theragra chalcogramma). ICES J Mar Sci 57:272-278

> Wiig O, Gjertz I, Griffiths D, Lydersen C (1993) Diving patterns of an Atlantic walrus Odobenus rosmarus rosmarus near Svalbard. Polar Biol 13:71-72

Zach R, Falls JB (1976) Ovenbirds (Aves: Parulidae) hunting behavior in a patchy environment: an experimental study. Can J Zool 54:1863-1879

Zeppelin TK, Ream RR (2006) Foraging habitats based on the diet of female northern fur seals (Callorhinus ursinus) on the Pribilof Islands, Alaska. J Zool 270:565-576

Submitted: December 4, 2009; Accepted: Jun 8, 2010

Proofs received from author(s): July 28, 2010 